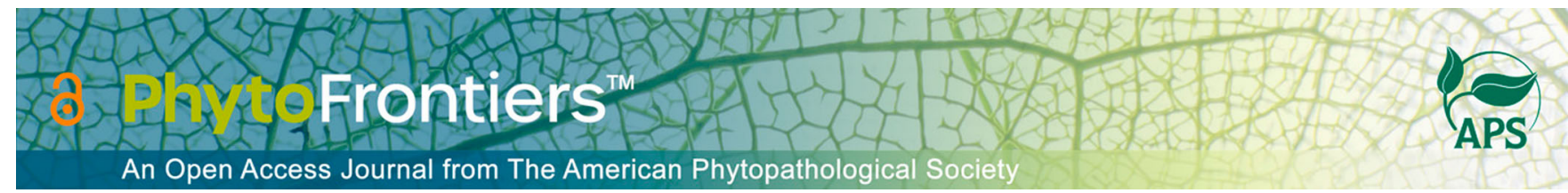

\title{
Research
}

\section{Revisiting the Source of Wilt Symptoms: X-Ray Microcomputed Tomography Provides Direct Evidence That Ralstonia Biomass Clogs Xylem Vessels}

\author{
Brian Ingel $^{1} \mid$ Denise Caldwell ${ }^{2}$ | Fiona Duong ${ }^{3}$ | Dilworth Y. Parkinson ${ }^{4} \mid$ Katherine A. McCulloh ${ }^{5}$ | \\ Anjali S. Iyer-Pascuzzi² ${ }^{2}$ | Andrew J. McElrone ${ }^{3,6}$ | Tiffany M. Lowe-Power ${ }^{1,7,+}$ (i) |
}

\author{
${ }^{1}$ Department of Plant Pathology, University of \\ California Davis, Davis, CA 95616 \\ 2 Department of Botany and Plant Pathology, \\ Purdue University, West Lafayette, IN 47907 \\ ${ }^{3}$ Department of Viticulture and Enology, \\ University of California, Davis, Davis, CA 95616 \\ ${ }^{4}$ Advanced Light Source Division, Lawrence \\ Berkeley National Laboratory, Berkeley, \\ CA 94720 \\ ${ }^{5}$ Department of Botany, University of \\ Wisconsin-Madison, Madison, WI 53706 \\ 6 USDA-Agricultural Research Service, Davis, \\ CA 95616 \\ 7 Department of Plant and Microbial Biology, \\ University of California Berkeley, Berkeley, \\ CA 94704
}

† Corresponding author: T. M. Lowe-Power; tlowepower@ucdavis.edu

Accepted for publication 23 July 2021.

Data availability: Representative, high-resolution cross-sections of each X-ray microCT reconstruction are available at http://doi.org/ 10.6084/m9.figshare.13287290 and http:// doi.org/10.6084/m9.figshare.13283933. The tomopy832.py script used to reconstruct the X-ray data is available at https://gist.github.com/ Ibluque/1bed77425fc531a882cfcca68dd3cb6e. The raw X-ray scatter data ( 1 to 10 gigabyte per file) and input parameters used in the reconstructions are available upon request.

\section{Funding}

Funding was provided to T. Lowe-Power (USDA NIFA Postdoctoral fellowship \#15148) and the lyer-Pascuzzi laboratory (FFAR New Innovator Award). This research used resources of the Advanced Light Source, which is a DOE Office of Science User Facility under contract no. DE-AC02-05CH11231.

$e$-Xtra: Supplementary figures are published online.

The author(s) declare no conflict of interest.

\begin{abstract}
Ralstonia causes wilt diseases by colonizing xylem vessels and disrupting water transport. The dogma is that bacterial biomass clogs vessels and reduces the flow of xylem sap due to Ralstonia abundance. However, the physiological mechanism of xylem disruption during bacterial wilt is untested. Using a tomato and Ralstonia pseudosolanacearum GMI1000 model, we visualized and quantified spatiotemporal dynamics of xylem disruption during bacterial wilt. First, we measured stomatal conductance of leaflets on mock-inoculated and wilt-symptomatic plants. Wilted leaflets had reduced stomatal conductance, as did turgid leaflets on the same petiole as wilted leaflets. Next, we used X-ray microcomputed tomography (X-ray microCT) and light microscopy to differentiate between mechanisms of xylem disruption: blockage by bacterial biomass, blockage by vascular tyloses, or sap displacement by gas embolisms. We imaged intact plant stems to quantify embolized vessels. Embolized vessels were rare, but infected plants with low bacterial populations had a nonsignificant trend of more vessel embolisms. To test whether vessels are clogged during bacterial wilt, we imaged excised stems after brief dehydration. Most vessels in mock-infected plants emptied their contents after excision, but nonconductive clogged vessels were abundant in infected plants by 2 days post infection. At wilt onset, when bacterial populations exceeded $5 \times 10^{8} \mathrm{CFU} / \mathrm{g}$ stem tissue, approximately half of the vessels were clogged with electron-dense bacterial biomass. We found no evidence of tyloses in X-ray microCT reconstructions or from light microscopy of preserved stems. Therefore, bacterial blockage of vessels appears to be the principal cause of xylem disruption during Ralstonia wilt.
\end{abstract}

Keywords: Ralstonia, bacterial wilt, xylem, X-ray microcomputed tomography 
Wilt diseases are destructive plant diseases that compromise xylem function and typically kill susceptible hosts (Lowe-Power et al. 2018; Yadeta and Thomma 2013). Wilt pathogens can disrupt xylem function by several potential mechanisms (LowePower et al. 2018). First, pathogens can directly clog vessels with their biomass. Second, plant defenses can block vessels. The living parenchyma cells adjacent to xylem vessels can grow balloonshaped structures called tyloses that obstruct the vessels. Tyloses can completely seal off xylem vessels in response to pathogen invasion or gas embolisms (De Micco et al. 2016). Additionally vascular parenchyma cells can secrete pectic polymers that form gels that impede pathogen and sap movement (De Micco et al. 2016). Although tyloses and gels can prevent the systemic spread of some pathogens, they are not effective at containing all pathogens and can cause collateral damage to the host by reducing the water transport capacity of the xylem (Ingel et al. 2020; Kashyap et al. 2020; Yadeta and Thomma 2013). Finally, vascular pathogens often secrete cellulases and pectinases (Gluck-Thaler et al. 2020; Liu et al. 2005; Schwarze and Landmesser 2000; Sun et al. 2011). These enzymes enable pathogens to move from vessel to vessel because the enzymes degrade the membranes within paired pits that connect vessels to each other (Pérez-Donoso et al. 2010). Pit membranes are semipermeable barriers composed of cellulose, hemicellulose, and pectin, and these polymers are more digestible than the polyphenolic lignin that reinforces vessel walls (Kaack et al. 2019). In addition to blocking large particles from moving vessel to vessel, pit membranes protect against the spread of gas embolisms (Choat et al. 2008; Tyree and Sperry 1989; Tyree and Zimmermann 2002). The narrow pores in pit membranes may allow the cohesive forces of water molecules to resist the entry of gases into sap-filled vessels (Sperry and Hacke 2004). Therefore, pathogen degradation of pit membranes may increase the xylem's vulnerability to embolism propagation. Increased incidence of vessel embolism has been reported for oak trees infected with the xylem-limited bacterial pathogen Xylella fastidiosa (McElrone et al. 2008).

Bacterial pathogens in the Ralstonia species complex (R. solanacearum, $R$. pseudosolanacearum, and $R$. syzygii) cause wilt diseases on a broad range of plants in the tropics and subtropics (Lowe-Power et al. 2020). Ralstonia are soilborne bacteria that invade plant roots and colonize the xylem before fatally wilting susceptible hosts (Caldwell et al. 2017). Ralstonia infection compromises the xylem's ability to transport water; before onset of wilt symptoms, plants have a decreased rate of water uptake from the soil (Denny et al. 1990). Light microscopy and histology show that tyloses are rare in Ralstonia-infected plants (Caldwell et al. 2017; Rahman et al. 1999; Vasse et al. 1995). Thus, the major cause of xylem disruption does not appear to be tyloses. In contrast, microscopy of infected roots and stems shows that Ralstonia grows extensively in the xylem and that bacterial cells and biofilm matrix are abundant within individual vessels (Caldwell et al. 2017). Furthermore, high populations of Ralstonia in stems (exceeding $10^{9} \mathrm{CFU} / \mathrm{g}$ tissue) are correlated with onset of wilt symptoms (Lowe-Power et al. 2018). Thus, existing data are consistent with a model that Ralstonia wilt reduces sap flow by clogging xylem vessels. However, this model has not been directly tested. As a counterpoint, the biofilm matrix of Ralstonia is highly fluidal (Dalsing and Allen 2014). A diagnostic sign of bacterial wilt disease is "bacterial streaming," where a bacterial ooze streams out from cut stems when suspended in water (García et al. 2019). Furthermore, Ralstonia biomass exudes with xylem sap when partially wilted tomato plants are de-topped. Therefore, it is possible that Ralstonia biomass is present in xylem vessels but does not impede the flow of sap.
Similar to other xylem-inhabiting bacteria (e.g., Xylella fastidiosa; McElrone et al. 2008), we wondered whether Ralstonia may increase the incidence of xylem vessel embolism in the early stages of disease progression. Like Xylella, Ralstonia degrades xylem pit membranes (Grimault et al. 1994; Ingel et al. 2019; Liu et al. 2005; Rahman et al. 1999; Roper et al. 2007). Additionally, most Ralstonia are facultative anaerobes that respire nitrate in the low-oxygen xylem (Dalsing et al. 2015; Prior et al. 2016). Nitrate respiration yields $\mathrm{N}_{2}$ gas, which has low aqueous solubility and may form gas bubbles that embolize vessels (Weiss 1970). Destructive methods, such as most microscopy assays, are not able to distinguish between air-filled vessels and sap-filled vessels.

Here, we use X-ray microcomputed tomography (X-ray microCT) to directly investigate the mechanism of xylem disruption during Ralstonia wilt of tomato. X-ray microCT yields 3-D views of tissue density at the micron resolution (McElrone et al. 2013). Because X-ray microCT imaging does not require destructive sample preparation, it is well suited to visualizing air-filled compartments in biological tissues. We coupled functional assays with X-ray microCT imaging to visualize the functionality of individual xylem vessels. We used X-ray microCT, microscopy, and quantitative PCR (ddPCR) to visualize and quantify bacterial populations in xylem vessels of Ralstonia-infected plants. Overall, our data support the model that Ralstonia clogs xylem vessels during wilt disease.

\section{MATERIALS AND METHODS}

\section{Bacterial growth conditions}

Four tomato pathogenic Ralstonia solanacearum species complex strains were used in this study: $R$. pseudosolanacearum GMI1000 (phylotype-sequevar clade: I-18), $R$. solanacearum K60 (clade IIA-7), $R$. solanacearum UW551 (clade IIB-1), and $R$. solanacearum UW163 (clade IIB-4). The bacteria were routinely cultured at $28^{\circ} \mathrm{C}$ on CPG media ( $10 \mathrm{~g} /$ liter of casamino acids, $1 \mathrm{~g} /$ liter of Bacto peptone, $1 \mathrm{~g} /$ liter of yeast extract, $5 \mathrm{~g} / \mathrm{liter}$ of glucose) with $0.002 \% \mathrm{w} / \mathrm{v}$ tetrazolium chloride.

\section{Measurement of stomatal conductance of tomato leaflets during wilt}

Susceptible tomato (S. lycopersicum cv. Bonny Best) seed was sown into Sunshine Ready Mix 4 and grown in a growth chamber with a constant temperature of $28^{\circ} \mathrm{C}$ and a $16 / 8 \mathrm{~h}$ day/night cycle. After 14 days, seedlings were transplanted into individual 4-inch pots. On the $17^{\text {th }}$ day, plants were soil-drench inoculated after lightly wounding the roots to synchronize infection (Khokhani et al. 2018). Bacterial inocula of GMI1000, UW551, K60, or UW163 were prepared from overnight cultures; cells were pelleted by centrifugation and resuspended in water to $\mathrm{OD}_{600}=0.2$. Roots were lightly wounded by gently lifting the plant stem, and $50 \mathrm{ml}$ of the inoculum was poured into the soil. Control plants were wounded and inoculated with pure water.

At 3 to $4 \mathrm{dpi}$, stomatal conductance was measured on individual leaflets of partially wilted Ralstonia-infected plants and on mock-inoculated nonwilted plants with a Licor 6400XT gas analyzer outfitted with a broadleaf chamber. Measurements occurred over the course of $3.5 \mathrm{~h}$ from 2 to $5.5 \mathrm{~h}$ post-light onset within the growth chamber. The Licor 6400XT was run with settings that matched the measured environmental values of the growth chamber: 700-ppm reference $\mathrm{CO}_{2}, 350-\mu \mathrm{mol} \mathrm{m} \mathrm{m}^{-2} \mathrm{~s}^{-1}$ light intensity, $400-\mu \mathrm{mol} \mathrm{s}^{-1}$ airflow, and chamber temperature at $27^{\circ} \mathrm{C}$ to match thermocouple measurements of leaf temperature. 
Individual leaflets were enclosed in the gas analyzer chamber, and stomatal conductance was recorded at equilibrium. To account for diurnal changes in stomatal conductance, mock-inoculated and Ralstonia-infected plants were measured in alternating blocks of one to two plants. On each mock-inoculated plant, three to four leaflets on individual petioles were measured; all leaflets of these plants were turgid. Leaflets on Ralstonia-infected plants with three phenotypes were targeted for measurements: "turgid" leaflets located on a petiole without any wilted leaflets, "wilted" leaflets, and "turgid near wilted," which were visually turgid leaflets that shared a petiole with wilted leaflets (Fig. 1). The sample size per condition varied based on wilt symptom distribution of the plant (i.e., not all symptomatic plants had petioles with both wilted and turgid leaflets).

\section{X-ray microcomputed tomography}

To prepare infected plants with a range of bacterial burdens and mock-inoculated plants to be imaged by X-ray microCT during a single 8- to 12-h imaging session, plants were inoculated by the cut-petiole method 1 or 2 days before the imaging session (Khokhani et al. 2018). This cut-petiole inoculation method was used because it yields highly synchronized disease progression relative to the stochastic disease progression of soil-drench inoculations. Strain GMI1000 was chosen for these studies because it is a model $R$. pseudosolanacearum strain.

Susceptible tomato ( $S$. lycopersicum cv. Money Maker) seed was sown into Sunshine Ready Mix 4 and grown in a greenhouse. After 14 days, seedlings were transplanted into individual 4-inch pots and returned to the greenhouse. At 25 and 26 days post sowing, tomato plants with three to four petioles were inoculated by excising the oldest petiole with a razor blade and carefully reverse-pipetting a $2-\mu$ l bacterial suspension $\left(1 \times 10^{4}\right.$ or $1 \times 10^{6}$ total colony forming units per plant). Mock-inoculated plants were inoculated with a droplet of sterile water. Inoculated plants were then grown for 1 to 2 days in an E15 Conviron growth chamber with a constant temperature of $28^{\circ} \mathrm{C}$ and $16 / 8 \mathrm{~h}$ day/night cycle.

Plants were imaged at the Lawrence Berkeley National Laboratory Advanced Light Source (ALS) X-ray microCT facility (beamline 8.3.2). Samples were continuously rotated $180^{\circ}$ while scanned by a $21 \mathrm{keV}$ synchrotron X-ray beam as described in McElrone et al. (2013). Per $180^{\circ}$ rotation, 769 to 1,313 longitudinal images were acquired by a CMOS camera (PCO.edge; $\mathrm{PCO}$ AG, Kehlheim, Germany) at 250- to 500-ms exposure time. Image resolution was 1.3 or $3.25 \mu \mathrm{m}$ per pixel depending on whether the stem diameter allowed it to be scanned at $5 \times$ or $2 \times$ magnification. Reconstructed cross-section images were analyzed in ImageJ.

Two experimental designs were used to visualize the anatomy and physiology of the stem vasculature during bacterial wilt disease.

\section{Experiment A: Visualization of vascular system of plants with intact roots and leaves}

One trial of this experiment was performed. Intact plants at the three-leaf stage were stabilized between Styrofoam blocks on a custom rig to prevent movement during imaging. The stem was imaged $2 \mathrm{~mm}$ above the inoculation site. Three mock-inoculated and seven $R$. pseudosolanacearum GMI1000-inoculated plants with a range of symptoms were imaged. Reconstructed crosssection images were analyzed in ImageJ to quantify the number of embolized vessels (appear black in the images; Supplementary Fig. S1A).

\section{Experiment B: Visualization of vascular system of dehydrated, excised stem}

Two trials of this experiment were performed. To visualize the water-conducting capacity of vessels, a $2.5-\mathrm{cm}$ stem segment was cut $1.25 \mathrm{~cm}$ above and below the inoculated petiole, which exposed the disrupted xylem vessels to air. The segments were briefly dehydrated under a heat lamp for $25 \mathrm{~min}$, which allowed the sap-conducting vessels to become air-filled.

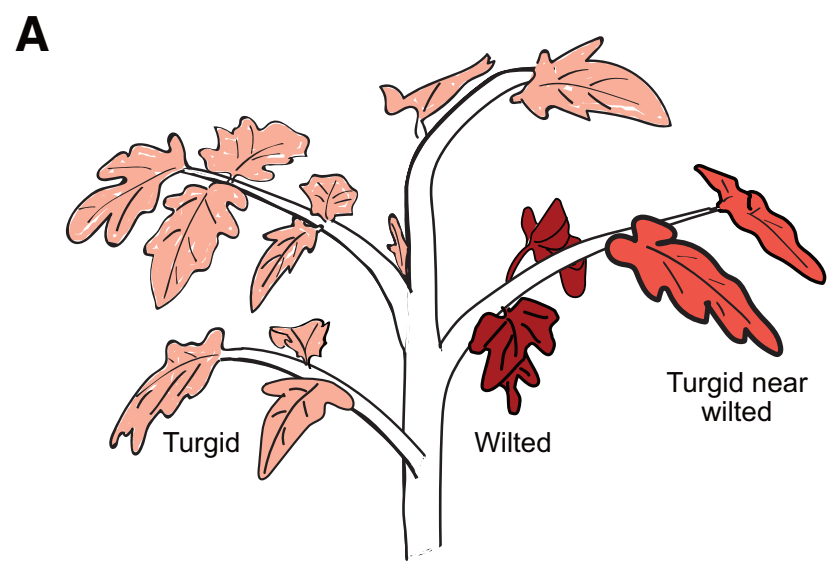

B Mock

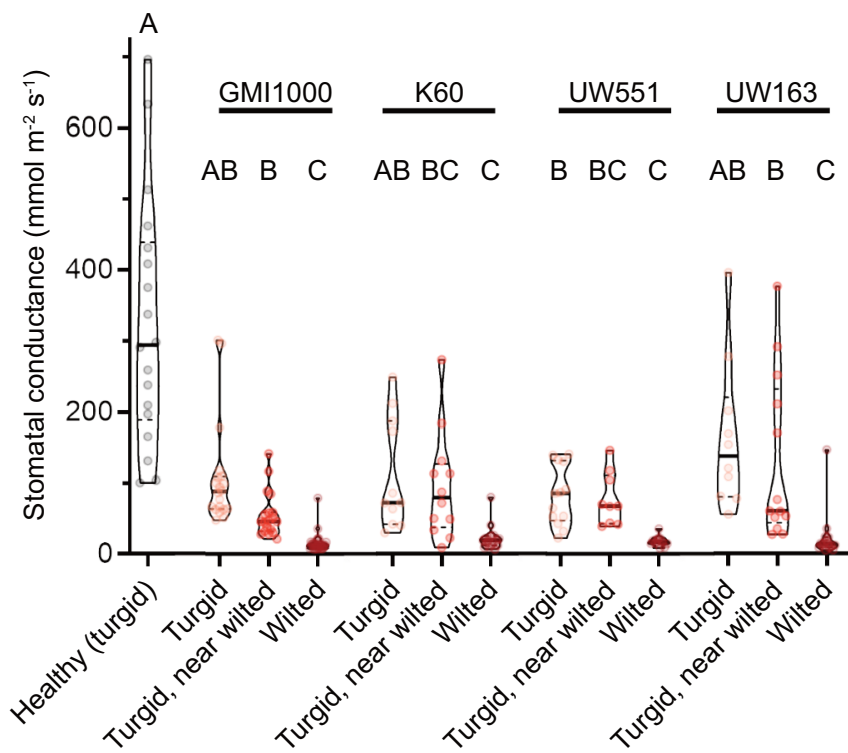

FIGURE 1

Leaf wilt status and proximity to wilt reflects a stepwise decline in stomatal conductance. Plants were soil-drench inoculated with either Ralstonia pseudosolanacearum GMI1000, $R$. solanacearum K60, $R$. solanacearum UW551, or $R$. solanacearum UW163 or mock-inoculated with water. Stomatal conductance of leaflets was measured with a Licor 6400XT gas analyzer. Infected plants were sampled on the first day of wilt onset ( 3 to 4 days after infection). A, Leaflets on the infected plant were categorized as turgid, wilted, or "turgid near wilted" if visually turgid but on the same petiole as wilted leaflets. B, Stomatal conductance of leaflets on mock-inoculated or partially wilted Ralstonia-infected tomato plants. At least three leaflets of 6 to 10 plants were sampled per condition. Statistics: Letters indicate significance of pairwise comparisons using ANOVA with Tukey's multiple comparison's test. 
In contrast, clogged vessels would not become air-filled. The stem segments were then loaded onto a drill chuck X-ray microCT rig and imaged. Reconstructed cross-section images were analyzed in Image J to determine the number of unclogged vessels (appear black in the images) and clogged vessels (appear whiter than the background tissue in the images; Supplementary Fig. S1B).

\section{Bacterial quantification by digital droplet PCR}

A Pseudomonas syringae digital droplet PCR (ddPCR) protocol (Morella et al. 2018) was modified to quantify Ralstonia solanacearum population sizes in tomato stem homogenate. The universal Ralstonia primers 759 (5'-GTCGCCGTCAACTCA TTTCC) and 760 (5'-GTCGCCGTCAGCAATGCGGAATCG) that amplify a $281 \mathrm{bp}$ band (Opina et al. 1997) were used. A mastermix was prepared with QX200 ddPCR EvaGreen Supermix (Bio-Rad), $250 \mathrm{nM}$ each of 759/760 primers, and $2 \mu \mathrm{l}$ of template (pure DNA or bacterial cells for a colony PCR approach). Oil-encapsulated droplets were generated in a Bio-Rad droplet generator per manufacturer's protocol before PCR amplification. Thermocycler conditions for the PCR were $95^{\circ} \mathrm{C}$ for $2 \mathrm{~min}$; 40 cycles of $94^{\circ} \mathrm{C}$ for $20 \mathrm{~s}, 60^{\circ} \mathrm{C}$ for $20 \mathrm{~s}$, and $72^{\circ} \mathrm{C}$ for $15 \mathrm{~s}$; and $72^{\circ} \mathrm{C}$ for $5 \mathrm{~min}$. Amplified samples were analyzed on the Bio-Rad droplet reader following the manufacturer's instructions, and Bio-Rad software was used for data analysis as described (Morella et al. 2018).

Before quantifying bacterial populations in the X-ray microCT imaged experimental samples, the ddPCR protocol was optimized as follows. Briefly, standard curves of $R$. solanacearum cells at known concentrations $\left(1 \times 10^{3}\right.$ to $1 \times 10^{5}$ cells per ddPCR reaction) were added to either tomato stem homogenate (30 mg of stem in $1 \mathrm{ml}$ of water), a 1:10 dilution of the homogenate, or water. The undiluted homogenate inhibited the PCR reaction, but reactions of the 1:10 homogenate and water accurately reflected bacterial concentration.

For experimental samples, stem tissue (19 to $40 \mathrm{mg}$ ) just above the site of inoculation was placed on wet ice immediately after $\mathrm{X}$-ray microCT imaging and was frozen within $12 \mathrm{~h}$. Samples were thawed and homogenized in $1 \mathrm{ml}$ of water in a BioSpec Mini BeadBeater- 8 shaking bead mill with four 2.2-mm metal beads for $90 \mathrm{~s}$. Homogenate was statically incubated for $5 \mathrm{~min}$ to allow plant biomass to settle before diluting the sample 1:10. Two microliters of the diluted homogenate was used as template DNA in the reactions.

\section{Microscopy and counting vessels}

Samples from one trial of the excised stem experiment were preserved for histochemical staining and light microscopy. After imaging, the portion of the stem tissue that was secured in the drill chuck was preserved in $70 \%$ ethanol. Samples were stored at room temperature until prepared for microscopy as described in Caldwell et al. (2017). Briefly, samples were further dehydrated with a graded series of alcohols, embedded in paraffin, and further mounted in the microtome sample holder. Once the paraffin block was constructed, the sample was cut using a rotary microtome and the cut samples were placed on a glass slide for light microscopy. A polychromatic dye, $0.05 \%$ toluidine blue, was used to assist in visualization of bacteria within plant tissues. When a region of interest was identified, paraffin samples were then recut using the protocol described in Caldwell et al. (2017). Light microscopy images were captured using an Olympus CX43 microscope and the SPOT Idea CMOS camera. Images were sent to UC Davis for analysis and counting. Vessels were visually inspected for the presence of Ralstonia and counted based on the degree of Ralsto- nia colonization: Open-absent (an open vessel without Ralstonia); Open-Ralstonia present (an open vessel with a low concentration of Ralstonia congregating at the vessel wall); Ralstonia partially occluded (a vessel where Ralstonia has colonized beyond the vessel wall and is forming an occlusion but has not fully occluded the vessel); and Ralstonia fully occluded (a vessel that is fully occluded by Ralstonia; Supplementary Fig. S9).

\section{RESULTS}

\section{Tomato xylem function progressively decreases as wilt symptoms become more severe}

Bacterial wilt disease of tomato is characterized by a progressive and rapid wilting of leaflets over a period of days to a week. At wilt onset, plants have spatial heterogeneity in the turgidity of leaflets. We hypothesized that there is a correlation between vascular decline and symptom onset. To characterize the water status of leaflets, we quantified stomatal conductance in individual leaflets of mock-inoculated and wilt-symptomatic plants. Stomatal aperture, which largely determines stomatal conductance, is actively regulated based on the leaf's water status and is a reliable indirect metric of the functional status of the xylem vessels that supply each leaf with water (Brodribb et al. 2017).

Susceptible tomato plants were inoculated via soil drench with R. pseudosolanacearum GMI1000 or mock inoculated with water. At symptom onset (3 to $4 \mathrm{dpi}$ ), stomatal conductance was measured (Fig. 1). On wilt-symptomatic plants, leaflets were classified as "wilted," "turgid near wilted" (i.e., turgid leaflets located on petioles with wilted leaflets), or "turgid" if located on petioles without symptoms (Fig. 1A). Stomatal conductance of leaflets correlated with wilt severity (Fig. 1B). Turgid leaflets on mock-inoculated plants had the highest stomatal conductance (median: $294 \mathrm{mmol} \mathrm{m}^{-2} \mathrm{~s}^{-1}$ ), and wilted leaflets had the lowest stomatal conductance (median: $12 \mathrm{mmol} \mathrm{m}^{-2} \mathrm{~s}^{-1}$ ). For turgid leaflets on symptomatic plants, there was a trend of lower stomatal conductance in leaflets that were colocated on petioles with wilted leaflets. Overall, stomatal conductance of leaflets matched the spatial heterogeneity in wilt symptoms.

We hypothesized that progressive declines in leaflet stomatal conductance was a general characteristic of bacterial wilt disease of tomato. We tested this by infecting tomato plants with three additional Ralstonia strains from different phylotype-sequevar clades: $R$. solanacearum K60 (clade IIA-7), $R$. solanacearum UW163 (clade IIB-4), and $R$. solanacearum UW551 (clade IIB-1). Tomato plants infected with the $R$. solanacearum strains showed results similar to those of plants infected with $R$. pseudosolanacearum GMI1000 (clade I-18; Fig. 1B). These results suggest that the stepwise disruption of functional tomato xylem vessels is a common occurrence in Ralstonia-mediated bacterial wilt of tomato and not limited to the I-18 clade.

\section{Gas embolisms are rare in Ralstonia-infected tomato xylem}

$\mathrm{X}$-ray microCT enables nondestructive 3-D imaging of the density of biological tissues. We used X-ray microCT to visualize xylem vessels in stems of intact plants. We imaged the stems of mock-inoculated tomato plants and plants infected with $R$. pseudosolanacearum GMI1000 while the plants were rotated $180^{\circ}$ in an X-ray beam. We reconstructed the samples in 3-D and investigated the lumina of xylem vessels. The images of the 10 plants each showed over 50 total xylem vessels (Supplementary Figs. S1A and S2). The xylem vessels were outlined by dense (whiter) rings of lignified tissue, and the lumina of most vessels were gray, indicating that they were filled with xylem sap. A few vessel lu- 

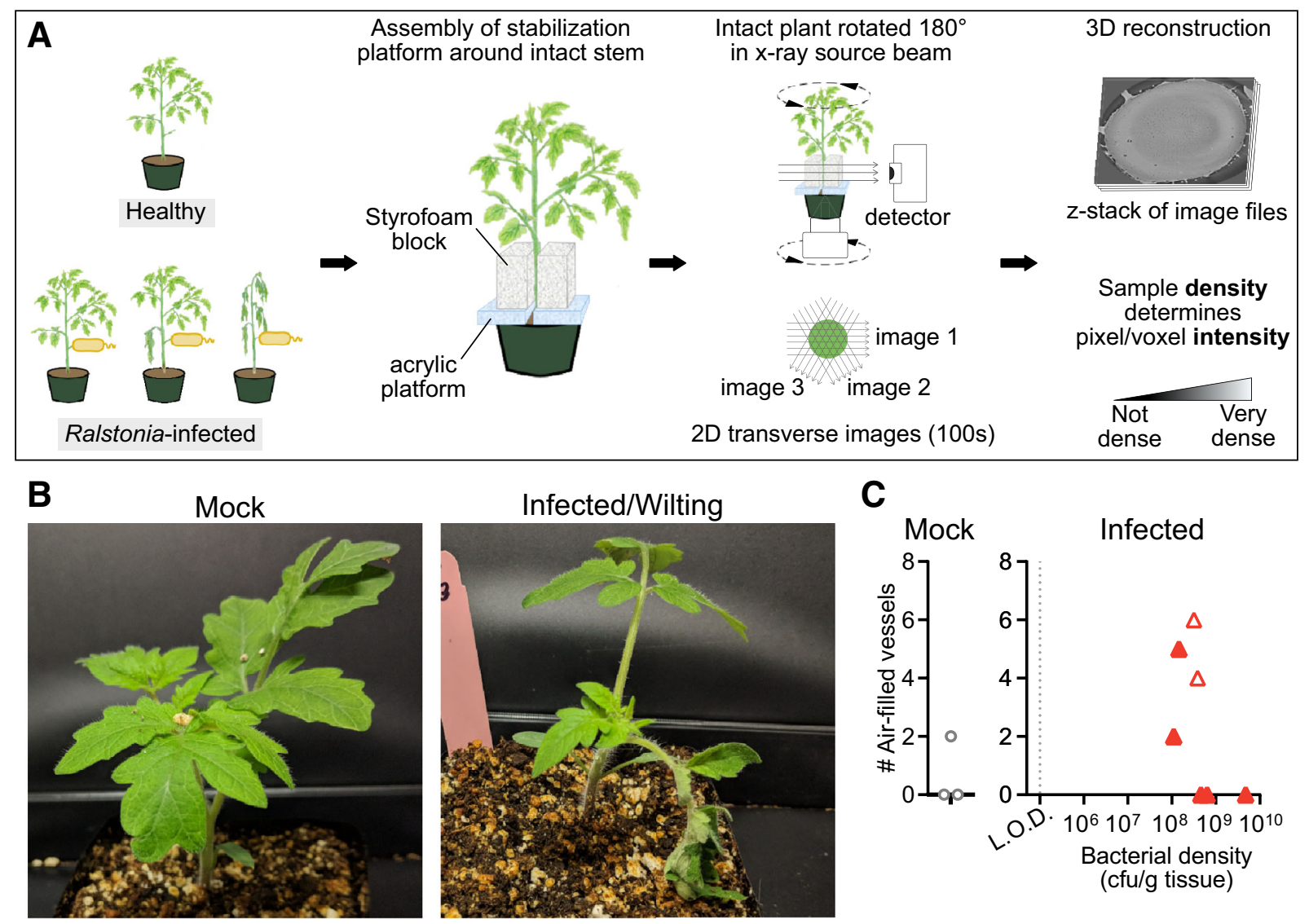

\section{C}
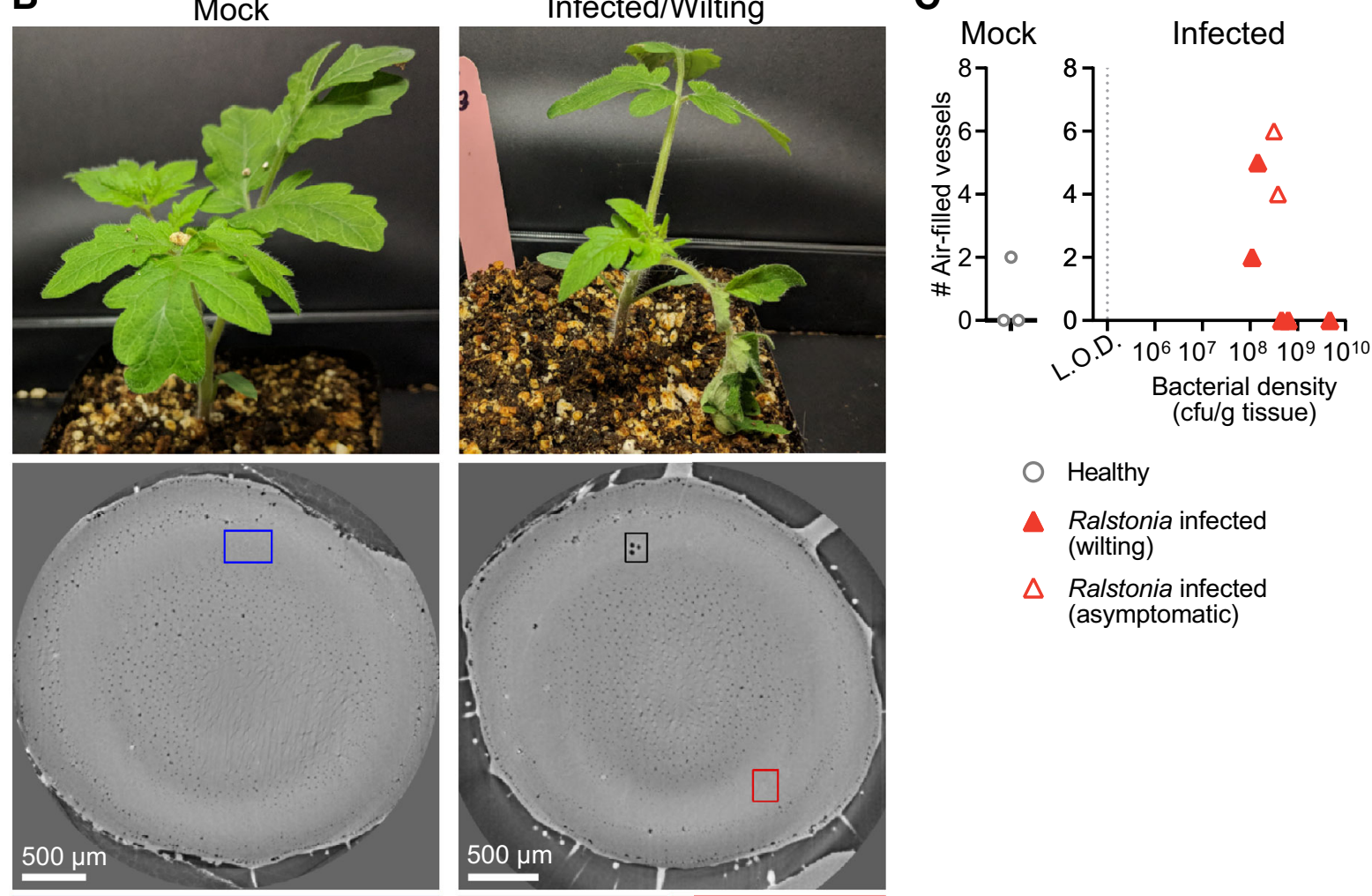

Healthy

$\triangle$ Ralstonia infected (wilting)

$\triangle$ Ralstonia infected (asymptomatic)
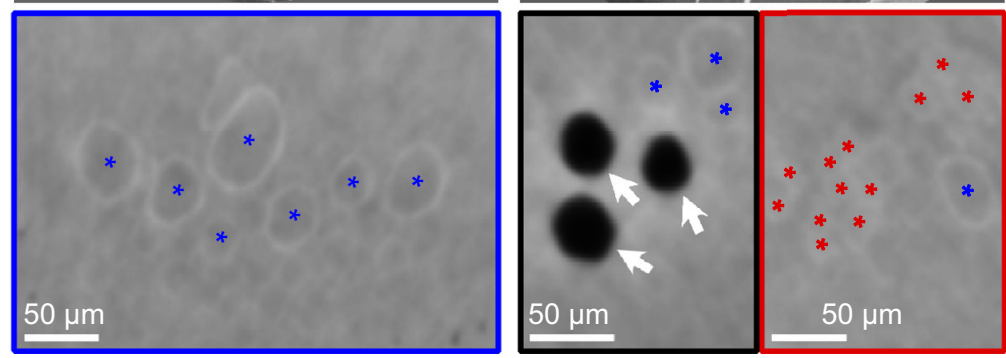

\section{FIGURE 2}

X-ray microcomputed tomography (microCT) imaging of tomato stem on intact plants reveals bacterial wilt disease increases density of vessel lumina and is only rarely associated with gas embolisms. The stem xylem of tomato plants was inoculated with water or $10^{4}$ CFU Ralstonia pseudosolanacearum GMI1000 via a cut petiole inoculation. Stems on plants with intact root and leaf systems were imaged via X-ray microCT ( $N=3$ mock-inoculated plants and $N=7$ Ralstonia-infected pants). A, Overview of experiment. B, Representative images of whole plants and X-ray microCT reconstructions of stem cross-sections of a mock-inoculated and Ralstonia-infected plant. Cross sections are located near where the inoculated petiole connects to the main stem. Vascular bundles in the boxed regions are shown at higher resolution in the bottom row. White arrows point to air-filled (embolized) vessels. Colored asterisks $\left(^{*}\right)$ indicate vessels filled with material of varying density. Blue asterisks: gray lumina. Red asterisks: lumen content with a high density similar to the lignified vessel wall. Supplementary Fig. S2 shows X-ray microCT reconstructions from all samples.

Supplementary Fig. S3 plots the relative pixel intensity of clogged, sap-filled, and air-filled xylem vessels. C, The number of air-filled (embolized) vessels in stems with varying bacterial population density. Bacterial density was quantified with digital droplet PCR. The dashed grey line shows the limit of detection (LOD). 


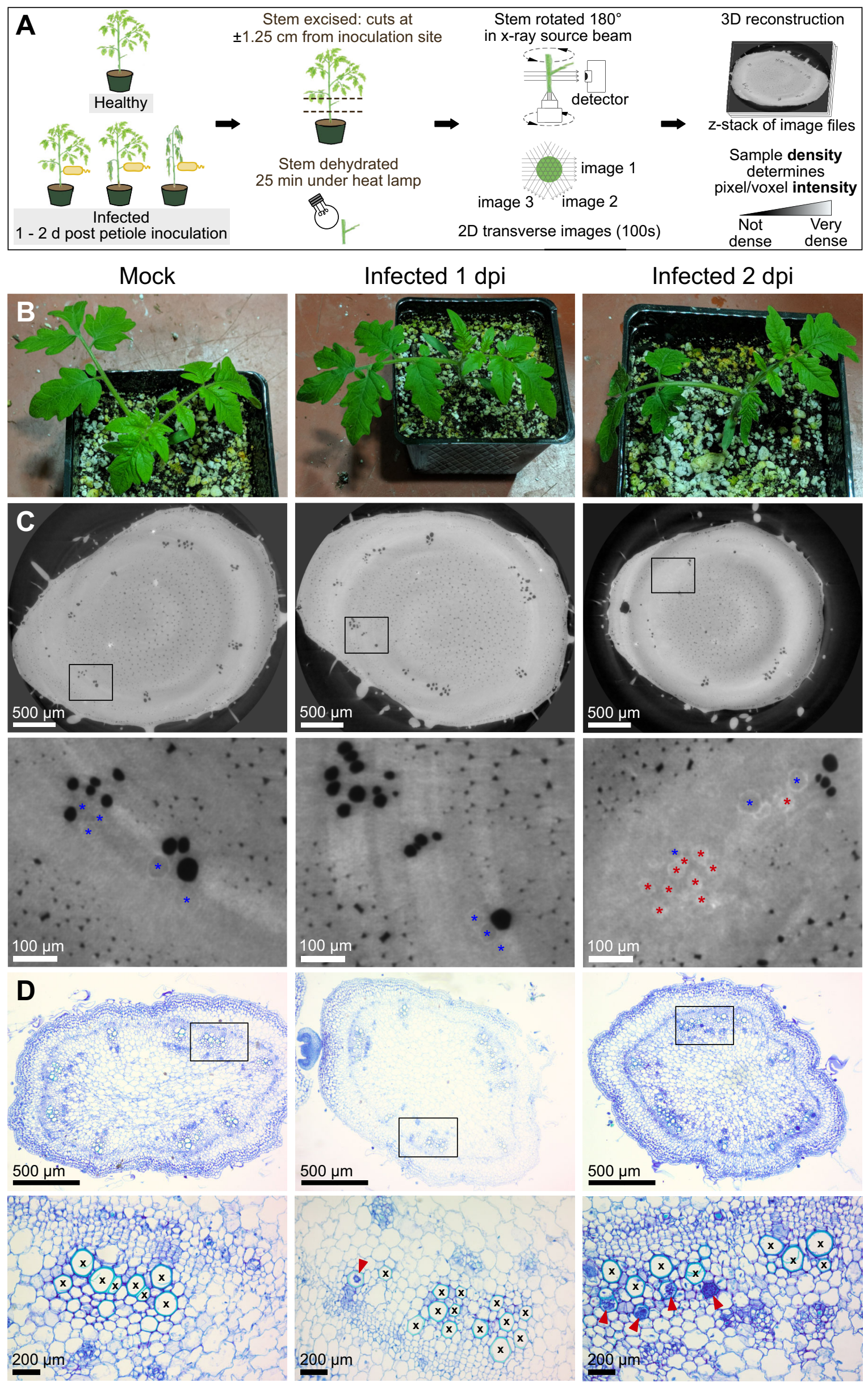


mina were filled with gas embolisms (Fig. 2, Supplementary Fig. S2), which were black owing to the density of gas being lower than the density of hydrated plant tissue (Supplementary Fig. S3). One of three mock-inoculated plants had two embolized vessels, whereas the other two had none. Four of seven Ralstonia-infected plants had two to six embolized vessels (Fig. 2C, Supplementary Fig. S2). The four infected plants with embolized vessels had a nonsignificant trend of lower bacterial burdens $\left(1.1 \times 10^{8}\right.$ to $\left.3.8 \times 10^{8} \mathrm{CFU} / \mathrm{g}\right)$ than the three infected plants without embolized vessels $\left(4.6 \times 10^{8}\right.$ to $\left.4.7 \times 10^{9} \mathrm{CFU} / \mathrm{g}\right)$. Bacterial burden was determined by digital droplet PCR from frozen samples because tissue could not be immediately homogenized for dilution plating, and it was unknown whether the X-ray exposure would affect bacterial viability.

Close inspection of the vascular bundles revealed that wiltsymptomatic plants had many xylem vessels with lumina that were filled with a substance denser than xylem sap and similar in density to the lignified wall (Fig. 2B, red asterisks; Supplementary Fig. S3). In contrast, vessels in mock-inoculated plants had a white, dense ring (lignin) that surrounded gray lumina (Fig. 2B, Supplementary Fig. S3). We hypothesized that the dense occlusions in wilt-symptomatic vessels were bacterial biomass clogs within vessels.

\section{Dense physical obstructions clog tomato xylem vessels}

To test the hypothesis that bacterial biomass clogs xylem vessels and inhibits sap transport, we coupled a functional assay with the X-ray microCT imaging. To determine how many vessels were capable of sap transport, we excised stems from plants and briefly dehydrated them before X-ray imaging (Fig. 3). During the dehydration, xylem sap would evaporate from the unclogged xylem vessels, but the bacterial polysaccharides from clogged vessels would resist desiccation and remain in the xylem vessel (Fig. 3C). To synchronize infection, plants were inoculated by a cut-petiole method, where $10^{4} \mathrm{CFU}$ or $10^{6} \mathrm{CFU}$ of $R$. pseudosolanacearum GMI1000 (or water) was directly introduced into the stem xylem. In the first trial, we imaged stems from mock-inoculated plants and infected plants 1 day post inoculation (dpi) and $2 \mathrm{dpi}$ with $10^{4} \mathrm{CFU}$. In the second trial, we imaged stems from the same conditions and added an additional condition where plants were inoculated with a higher dose of Ralstonia $\left(10^{6} \mathrm{CFU}\right)$ and imaged at $2 \mathrm{dpi}$.

We quantified the number of sap-conducting vessels from X-ray microCT cross-sections (Figs. 3 and 4A, Supplementary Figs. S1B and S4 to S7). As expected, the majority of xylem vessels in mock-inoculated plants released their contents during dehydration. In trial 1, mock-inoculated plants had 59 to 81 functional vessels (Fig. 4A and S4). In the second trial, mock- inoculated plants had 114 to 133 functional vessels because the plants grew faster prior to inoculation (Fig. 4A). Stems from the 1 dpi infected plants and the mock-inoculated plants had similar numbers and distributions of sap-conducting vessels in both trials (Fig. 4A). By 2 dpi, infected plants (both asymptomatic and symptomatic) had fewer black, air-filled vessels in both trials, indicating fewer sap-conducting vessels $(P<0.05$, Kruskal-Wallis test with Dunn's multiple comparison's test; Fig. 4A). In trial 2, the 2 dpi plants inoculated with the high titer of bacteria $\left(10^{6}\right.$ $\mathrm{CFU}$ ) had fewer sap-conducting vessels than the 2 dpi plants inoculated with the moderate titer $\left(10^{4} \mathrm{CFU}\right.$; Fig. 4A). Furthermore, many of the 2 dpi stems from infected plants in both trials had large regions that lacked any sap-conducting vessels (Supplementary Figs. S6 and S7).

Close inspection of the 2 dpi reconstructions revealed that many vessels in the excised stems had dense, white lumina (Fig. 3) similar to those visualized in the intact stems of infected plants (Fig. 2B), indicating that these vessels were occluded. To investigate the occlusions further, we transected the 3-D X-ray microCT reconstructions to view vessels longitudinally (Fig. 5 and S8). When viewed from the side, it was clear that the white occlusions were continuous within the tapered xylem vessels. This suggested that the occlusions were a dense gel formed by bacterial biofilms seen in our and others' previous microscopic analyses of Ralstonia-infected stems (Caldwell et al. 2017; Planas-Marquès et al. 2020; Vasse et al. 1995).

Additionally, small lesions were visible near the inoculation site in some of the 2 dpi samples from both trials but not in the mock-inoculated or $1 \mathrm{dpi}$ samples (Fig. 4B). These lesions were irregularly shaped and larger than the 10- to 40- $\mu \mathrm{m}$, ovalshaped xylem vessels. In trial 2 , these lesions were more common in the 2 dpi plants inoculated with the high titer of bacteria $\left(10^{6} \mathrm{CFU}\right)$ than with the moderate titer $\left(10^{4} \mathrm{CFU}\right)$. Internal lesions on tomato stems are an infrequent symptom of Ralstonia wilt of tomato (García et al. 2019). Lesions like these are often pigmented brown, suggesting that they are part of a plant defense response that involves the activity of polyphenolic oxidases (Beckman 1964).

\section{Histology of stem samples reveals abundant bacterial occlusions in xylem vessels}

We visualized preserved stem samples with a histochemical stain and light microscopy to determine whether the vessel occlusions were plant-derived gels and tyloses or bacterial biofilms. We embedded the stems in paraffin wax and stained slices with $0.05 \%$ toluidine blue, which stains the acidic xylem wall cyan and other neutral plant and bacterial tissues dark blue. We classified the lumen contents of each xylem vessel based on the abundance

\section{FIGURE 3}

X-ray microcomputed tomography (microCT) imaging of excised, dehydrated tomato stems reveals Ralstonia clogs vessels and reduces xylem vessel function. Tomato plants were inoculated with water or Ralstonia pseudosolanacearum GMI1000 (10 $\mathrm{CFU}$ or $10^{6}$ CFU) via a cut petiole inoculation and were imaged at 1 to $2 \mathrm{dpi}$. Before imaging with X-ray microCT, 2-cm segments of stem around the inoculation site were excised and dehydrated briefly to allow sap to evaporate from functioning xylem vessels. Two trials were performed with $N \geq 5$ plants per condition. A, Experimental overview. B to $\mathbf{D}$, Representative photographs of whole plants, X-ray microCT reconstructions of excised stems, and histology micrographs of preserved stems, respectively. Full images are available in Supplementary Figs. S4 to S7. C, Images show X-ray microCT cross-sections of stems near the petiole inoculation site, with black, air-filled vessels representing vessels that were sap-filled, functioning vessels prior to stem excision and dehydration. Black boxes are shown with enhanced resolution below each cross-section. Symbols indicate vessels filled with material of varying density. Blue asterisks: gray lumina with low-density contents. Red asterisks: lumen content with a high density similar to the lignified vessel wall. D, Preserved stems were stained with toluidine blue and imaged using light microscopy ( $4 \times$ magnification; top row). Black boxes are shown with enhanced magnification (20x; bottom row). Black Xs are displayed in open vessels free of occlusions, and red arrows indicate vessels partially or fully occluded by R. pseudosolanacearum GMI1000 (Supplementary Fig. S9). 
FIGURE 4

As bacterial wilt disease progresses, fewer vessels are functional, more vessels are occluded by bacterial biomass, and stem lesions develop. A, The number of sapconducting xylem vessels and bacterial density in the stems as measured in the excisedstem imaging assay. The number of sap-conducting vessels (air-filled, black) was quantified from the X-ray microcomputed tomography (microCT) reconstructions, and bacterial density was quantified by digital droplet PCR. The dashed gray line represents the limit of detection (LOD) of $1 \times 10^{5}$ CFU/g stem. Samples from mock-inoculated plants were graphed at the LOD. B, Vascular lesions near the point of inoculation (red arrow) were seen in the reconstructed $\mathrm{X}$-ray microCT cross-sections (left) and were much larger than xylem vessels (black arrow). Lesions were quantified for each sample in the excised stem assay (right). C, Quantification of vessel occlusions in histology micrographs from trial 1 of the excised stem assay. Letters below the graph indicate plant status when stem samples were taken: $\mathrm{A}=$ asymptomatic $\mathrm{W}=$ at least one leaf wilting.

$\mathbf{A}$

Trial 1

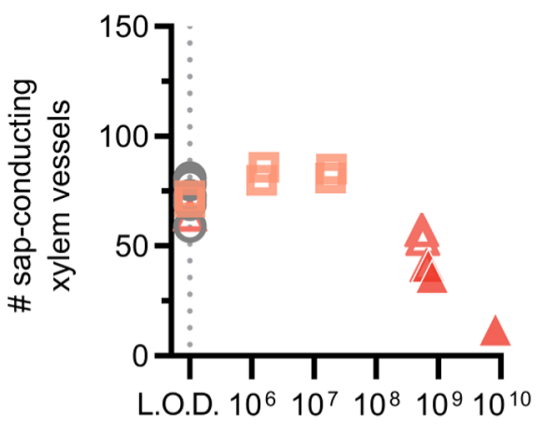

Bacterial Density in Stem (cfu / g stem)
Trial 2

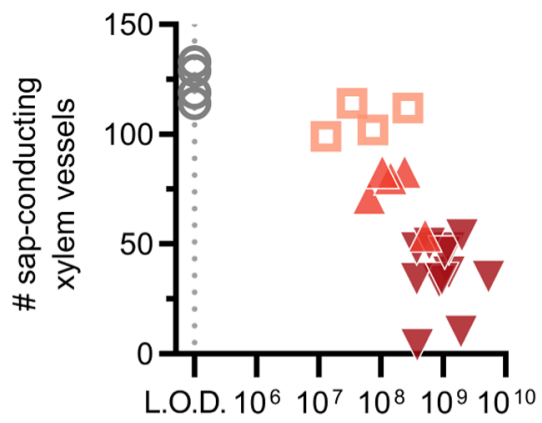

Bacterial Density in Stem (cfu / g stem)

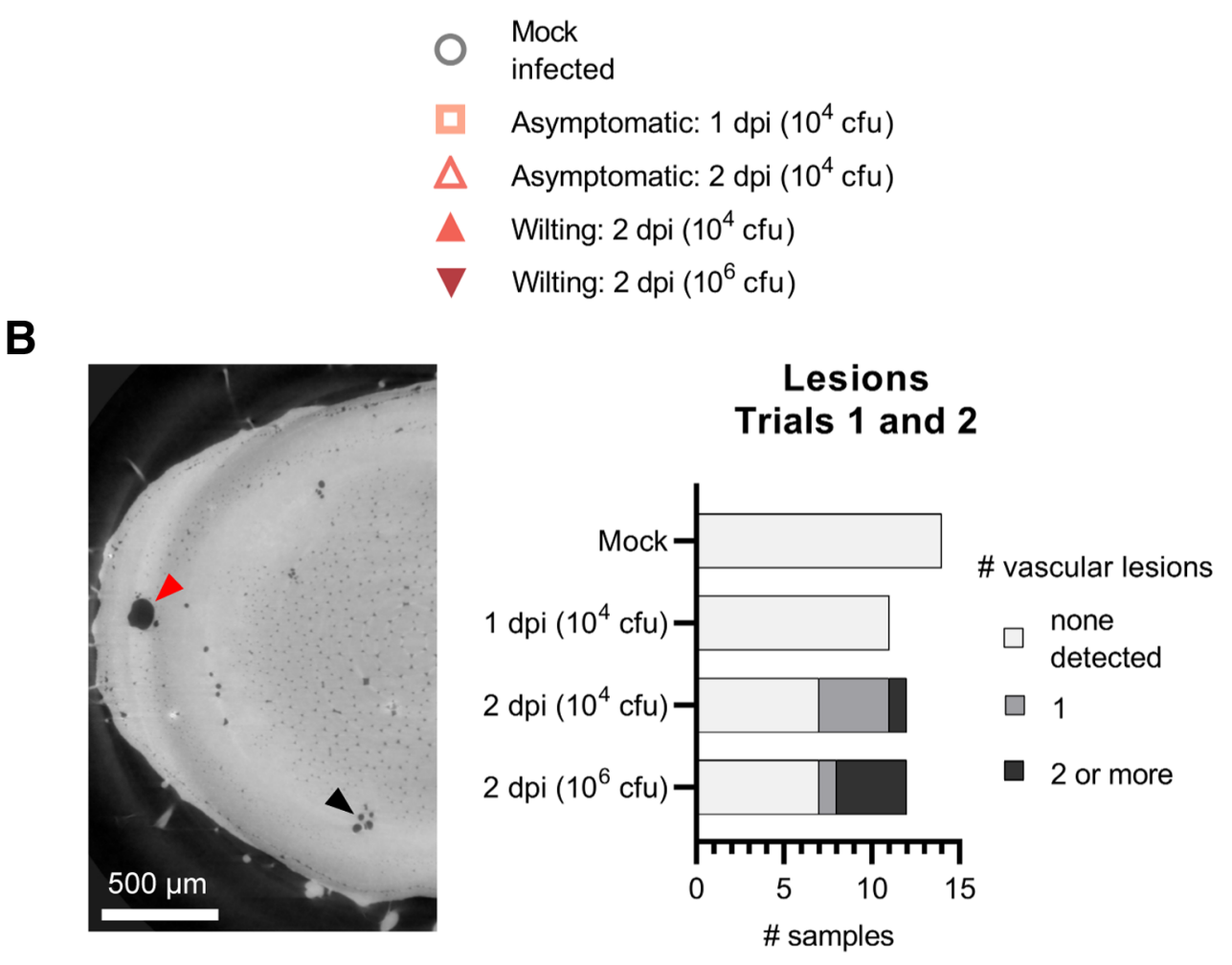

C

\section{Histology Trial 1}

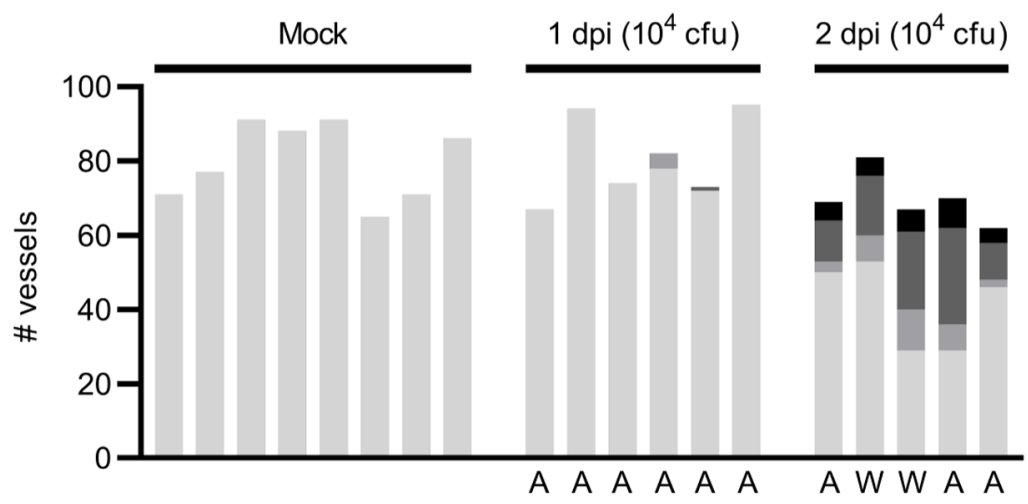

Vessel characteristics

Open - Ralstonia absent

Open - Ralstonia present
- Ralstonia partially occluded

- Ralstonia fully occluded 
of bacterial biomass within the vessel (Supplementary Fig. S9). Stems from mock-inoculated plants and most 1 dpi plants lacked obvious bacterial aggregates in the xylem (Figs. 3D and 4C). By 2 dpi, 23 to $49 \%$ of vessels were partially or fully occluded by Ralstonia aggregates, and another 3 to $16 \%$ of xylem vessels were visibly colonized with a few Ralstonia cells attached to the walls (Figs. 3D and 4C). Scanning electron microscopy (SEM) analysis of stem tissue confirmed the abundance of bacterial aggregates within xylem vessels (Supplementary Fig. S10). Overall, our results were consistent with the model that the bacterial clogs are
A
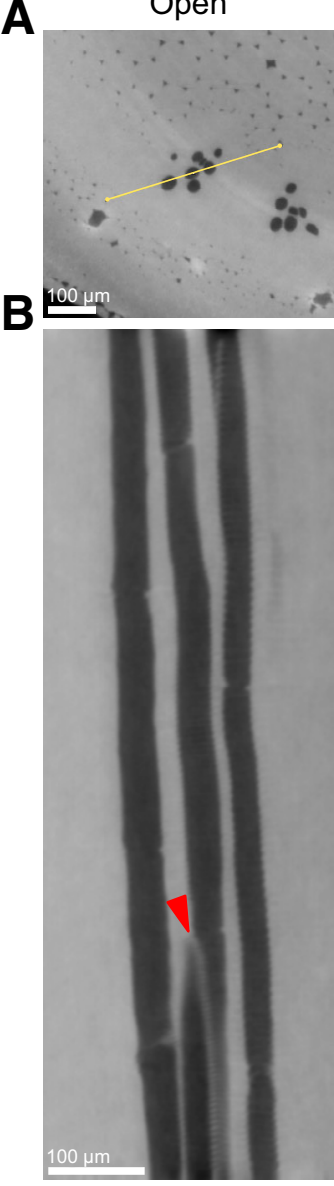

Sap-filled
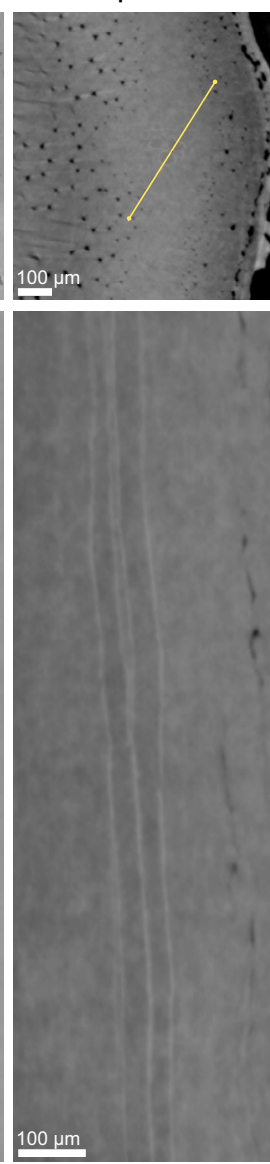

Occluded
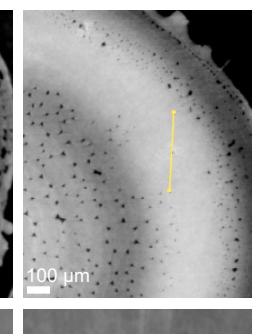

FIGURE 5

Longitudinal views of xylem vessels show that occlusions were continuous within individual vessels. A, Transverse X-ray microcomputed tomography (microCT) cross-sections showing open vessels (left), sap-filled vessels (middle), and occluded vessels (right). Yellow lines indicate the axis of longitudinal imaging in B. B, Stacks of transverse cross-sections were compiled and imaged along the longitudinal axes chosen in A. Longitudinal cross-sections of vessels classified as air-filled (left) in transverse cross-sections show that these vessels are filled with air along their length and continuously into connecting vessels via perforation plates (red arrow). Longitudinal cross-sections of vessels classified as sap-filled (middle) in transverse cross-sections show that these vessels are continuously sap-filled along their length. Longitudinal cross-sections of vessels classified as occluded (right) in transverse cross-sections show that these vessels are occluded along their length and continuously into connecting vessels via perforation plates (red arrow). This indicates that the occluding mass is able to move between vessels and clog entire vessel conduits. Samples used in this imaging analysis were H8 (left), HP4 (middle), and 2G4 (right); additional images are shown in Supplementary Fig. S8. the predominant mechanism of vascular disruption during bacterial wilt disease.

\section{DISCUSSION}

Wilt, scorch, blight, and other diseases associated with xylem dysfunction disrupt water transport capacity, causing substantial morbidity and mortality of plants (Aguirreolea et al. 1995; Beckman et al. 1962; Denny et al. 1990; Lorenzini et al. 1997; Rajagopal et al. 1987). Denny et al. (1990) determined that transpiration decreased as wilt symptoms appeared by weighing mock-inoculated and Ralstonia-infected tomato plants to measure water loss and estimate whole-plant transpiration rates. In the 1960s, Beckman, Brun, and Buddenhagen constructed an early prototype of a gas-exchange system that measured transpiration rates in Ralstonia-infected banana plants and demonstrated that Ralstonia disrupts water transport (Beckman et al. 1962). We measured the stomatal conductance of individual tomato leaflets to determine transpiration capability on a finer scale instead of broadly estimating whole-plant transpiration. Our results are consistent with the literature stating that Ralstonia wilt symptoms develop only after stomatal conductance decreases. However, stomatal conductance is not solely determined by leaf water potential; chemical signaling via abscisic acid can regulate stomatal aperture independently from leaf water potential (Kim et al. 2010). Therefore, we used X-ray microCT to reveal the ability of individual vessels to transport sap.

Although it is well demonstrated that wilt pathogens disrupt xylem sap transport (Yadeta and Thomma 2013), the exact mechanisms of xylem disruption are unknown for most pathosystems. Multiple physiological mechanisms can disrupt xylem water transport: plant-derived structures such as tyloses can block vessels, foreign bodies such as microbes and their biomass can clog vessels, and gas embolisms can displace sap (Lowe-Power et al. 2018). We used X-ray microCT and complementary methods to test the hypothesis that Ralstonia biomass clogs tomato xylem vessels.

Gas embolisms have been associated with drought stress and have been occasionally implicated in early stages of xylem infections (Brodersen et al. 2013; McElrone et al. 2008; Pérez-Donoso et al. 2016). Embolisms occur when air is aspirated into the water column, which can happen in damaged vascular tissues (Tyree and Sperry 1989). Vascular pathogens often secrete pectinases and cellulases that can degrade the xylem pit membranes that separate vessels from each other and separate vessels from parenchyma tissue (Brodersen et al. 2013; McElrone et al. 2008; Pérez-Donoso et al. 2016). It has been suggested that some plants are able to refill embolized vessels, although the mechanisms, frequency, and locations of refilling are currently the subject of much debate (Brodersen and McElrone 2013). The phloem-unloading hypothesis proposes that plants could repair embolisms by unloading mono- and disaccharides from the phloem into the xylem (Nardini et al. 2011). These osmolytes would drive water translocation into the vessel, which could dissolve the embolism. If plants divert nutrients into the xylem to ameliorate abiotic stresses, it is likely that some xylem pathogens manipulate this pathway through effectors or by inducing embolisms. We previously found that Ralstonia infection increases the concentration of nutrients in xylem sap (Lowe-Power et al. 2018). We speculated that Ralstonia's degradation of pit membranes (Grimault et al. 1994) might increase vessel embolism, which could trigger an embolism-repair process that increases solute concentration of sap. However, our X-ray microCT imaging of intact plants revealed that embolized vessels are rare in mock-infected or Ralstonia-infected plants. Clearly, embolism is 
not responsible for the mass hydraulic failure that induces wilt symptoms, but our data cannot rule out the possibility that vessel embolism occasionally precedes vessel clogging.

We did not observe tyloses in the xylem of Ralstoniainfected tomato plants, and our results are consistent with microscopy studies done by multiple groups showing that tyloses are rare in Ralstonia-infected tomato plants (Caldwell et al. 2017; Rahman et al. 1999; Vasse et al. 1995). In contrast, X-ray microCT and microscopy showed abundant tyloses in xylem vessels of grapevines symptomatic with a Xylella fastidiosa infection and in grapevines symptomatic with the Esca trunk disease complex caused by a community of multiple fungi (Bortolami et al. 2019; Ingel et al. 2020). Although tyloses can provide an effective defense against some pathogens (Kashyap et al. 2020), prolific tylose formation in the absence of new vessel development leads to xylem disruption and water stress (Fradin and Thomma 2006). A preponderance of evidence supports a new model that tyloses, and not bacterial blockages, are responsible for Pierce's disease symptoms in Xylella-infected grapevines (De Benedictis et al. 2017; Ingel et al. 2020; Pérez-Donoso et al. 2016; Stevenson et al. 2004; Sun et al. 2013). We speculate that the differential cause of symptoms between Ralstonia and Xylella is due to differences in population growth and behavior in their respective host environments. Ralstonia can clog xylem vessels by a combination of rapid population growth (exceeding $10^{9} \mathrm{CFU} / \mathrm{g}$ within a vessel after a few days) and considerable exopolysaccharide production (McGarvey et al. 1999). Conversely, Xylella populations grow at a relatively slow rate (reaching $10^{8} \mathrm{CFU} / \mathrm{g}$ after several months) and form aggregates within xylem vessels that often do not occlude the vessel (Baccari and Lindow 2011; Ingel et al. 2020). These factors allow the host plant to mount a defense response within the xylem (e.g., tyloses). However, it has been shown that tyloses are ineffective at containing Xylella. Instead, tyloses block an increasing number of vessels over time, resulting in xylem disruption (Ingel et al. 2020). The mechanism of xylem disruption in Esca is still unclear due to the complexity of the disease complex. Esca-diseased grapevines had elevated numbers of tyloses, and experiments with an X-ray contrasting agent in the xylem sap demonstrated that the tyloses were capable of blocking or diverting sap flow. However, the abundance of tyloses did not correlate with symptom severity in the small sample-sized study (Bortolami et al. 2019).

Overall, our data support the model that Ralstonia infections cause wilt symptoms because the pathogen's biomass clogs xylem vessels. Importantly, we visualized xylem vessels after both destructive and nondestructive sampling of tomato stems, which allowed us to infer the functional status of individual xylem vessels. X-ray microCT demonstrated that the vessels were clogged in tomato plants with high Ralstonia population sizes. Furthermore, histochemical microscopy and SEM showed that bacterial aggregates were abundant in the samples with the most clogged vessels. Consistently, Caldwell et al. (2017) showed histological staining of Ralstonia-clogged xylem vessels in susceptible tomato cultivars, whereas xylem vessels of resistant cultivars remained relatively open. Future studies that incorporate an X-ray contrasting agent such as iohexol (Bortolami et al. 2019) with X-ray microCT of Ralstonia-infected tomatoes or use xylem-mobile fluorescent probes (Endo et al. 2019) would enable quantification of sap flow rates in xylem vessels with copious versus minimal Ralstonia biomass.

\section{ACKNOWLEDGMENTS}

We sincerely thank multiple scientists for technical advice: Duncan Smith for Licor 6400XT training; Thorsten Knipfer, Clarissa Reyes,
Alastair MacDowell, and Harold Barnard for X-ray microCT training and support; and Jason Lowe-Power for computational training. Dr. Caitilyn Allen provided the facilities to measure stomatal conductance for all strains, including the R3B2 select agent strain UW551. Dr. Steven Lindow and Christina Wistrom provided access to and support for the CNR Oxford Tract Greenhouse where plants were grown for X-ray analysis. We thank Dr. Britt Koskella for access to their BioRad Droplet Digital PCR platform.

\section{LITERATURE CITED}

Aguirreolea, J., Irigoyen, J., Sánchez-Díaz, M., and Salaverri, J. 1995. Physiological alterations in pepper during wilt induced by Phytophthora capsici and soil water deficit. Plant Pathol. 44:587-596.

Baccari, C., and Lindow, S. E. 2011. Assessment of the process of movement of Xylella fastidiosa within susceptible and resistant grape cultivars. Phytopathology 101:77-84.

Beckman, C. H. 1964. Host responses to vascular infection. Annu. Rev. Phytopathol. 2:231-252.

Beckman, C. H., Brun, W. A., and Buddenhagen, I. W. 1962. Water relations in banana plants infected with Pseudomonas solanacearum. Phytopathology 52:1144.

Bortolami, G., Gambetta, G. A., Delzon, S., Lamarque, L. J., Pouzoulet, J., Badel, E., Burlett, R., Charrier, G., Cochard, H., Dayer, S., Jansen, S., King, A., Lecomte, P., Lens, F., Torres-Ruiz, J. M., and Delmas, C. E. L. 2019. Exploring the hydraulic failure hypothesis of esca leaf symptom formation. Plant Physiol. 181:1163-1174.

Brodersen, C. R., and McElrone, A. J. 2013. Maintenance of xylem network transport capacity: A review of embolism repair in vascular plants. Front. Plant Sci. 4:108.

Brodersen, C. R., McElrone, A. J., Choat, B., Lee, E. F., Shackel, K. A., and Matthews, M. A. 2013. In vivo visualizations of drought-induced embolism spread in Vitis vinifera. Plant Physiol. 161:1820-1829.

Brodribb, T. J., McAdam, S. A., and Carins Murphy, M. R. 2017. Xylem and stomata, coordinated through time and space. Plant Cell Environ. 40: $872-880$.

Caldwell, D., Kim, B.-S., and Iyer-Pascuzzi, A. S. 2017. Ralstonia solanacearum differentially colonizes roots of resistant and susceptible tomato plants. Phytopathology 107:528-536.

Choat, B., Cobb, A. R., and Jansen, S. 2008. Structure and function of bordered pits: New discoveries and impacts on whole-plant hydraulic function. New Phytol. 177:608-625.

Dalsing, B. L., and Allen, C. 2014. Nitrate assimilation contributes to Ralstonia solanacearum root attachment, stem colonization, and virulence. J. Bacteriol. 196:949-960.

Dalsing, B. L., Truchon, A. N., Gonzalez-Orta, E. T., Milling, A. S., and Allen, C. 2015. Ralstonia solanacearum uses inorganic nitrogen metabolism for virulence, ATP production, and detoxification in the oxygen-limited host xylem environment. mBio 6:e02471.

De Benedictis, M., De Caroli, M., Baccelli, I., Marchi, G., Bleve, G., Gallo, A. Ranaldi, F., Falco, V., Pasquali, V., Piro, G., Mita, G., and Di Sansebastiano, G. P. 2017. Vessel occlusion in three cultivars of Olea europaea naturally exposed to Xylella fastidiosa in open field. J. Phytopathol. 165:589-594.

De Micco, V., Balzano, A., Wheeler, E. A., and Baas, P. 2016. Tyloses and gums: A review of structure, function and occurrence of vessel occlusions. IAWA J. 37:186-205.

Denny, T. P., Carney, B. F., and Schell, M. A. 1990. Inactivation of multiple virulence genes reduces the ability of Pseudomonas solanacearum to cause wilt symptoms. Mol. Plant-Microbe Interact. 3:293-300.

Endo, S., Iwai, Y., and Fukuda, H. 2019. Cargo-dependent and cell wall-associated xylem transport in Arabidopsis. New Phytol. 222: 159-170.

Fradin, E. F., and Thomma, B. P. 2006. Physiology and molecular aspects of Verticillium wilt diseases caused by $V$. dahliae and V. albo-atrum. Mol. Plant Pathol. 7:71-86.

García, R. O., Kerns, J. P., and Thiessen, L. 2019. Ralstonia solanacearum species complex: A quick diagnostic guide. Plant Health Prog. 20:7-13.

Gluck-Thaler, E., Cerutti, A., Perez-Quintero, A., Butchacas, J., RomanReyna, V., Madhaven, V. N., Shantharaj, D., Merfa, M. V., Pesce, C., Jauneau, A., Vancheva, T., Lang, J. M., Allen, C., Verdier, V., Gagnevin, L., Szurek, B., Cunnac, S., Beckham, G., de la Fuente, L., Patel, H. K., Sonti, R. V., Bragard, C., Leach, J. E., Noël, L. D., Slot, J. C., Koebnik, R., and Jacobs, J. M. 2020. Repeated gain and loss of a single gene modulates the evolution of vascular plant pathogen lifestyles. Sci. Adv. 6:eabc4516.

Grimault, V., Gélie, B., Lemattre, M., Prior, P., and Schmit, J. 1994 Comparative histology of resistant and susceptible tomato cultivars infected by Pseudomonas solanacearum. Physiol. Mol. Plant Pathol. 44: 105-123. 
Ingel, B., Jeske, D. R., Sun, Q., Grosskopf, J., and Roper, M. C. 2019. Xylella fastidiosa endoglucanases mediate the rate of Pierce's disease development in Vitis vinifera in a cultivar-dependent manner. Mol. Plant. Microbe. Interact. 32:1402-1414.

Ingel, B., Reyes, C., Massonnet, M., Boudreau, B., Sun, Y., Sun, Q., McElrone, A. J., Cantu, D., and Roper, M. C. 2020. Xylella fastidiosa causes transcriptional shifts that precede tylose formation and starch depletion in xylem. Mol. Plant Pathol. 22:175-188.

Kaack, L., Altaner, C. M., Carmesin, C., Diaz, A., Holler, M., Kranz, C., Neusser, G., Odstrcil, M., Jochen Schenk, H., Schmidt, V., Weber, M., Zhang, Y., and Jansen, S. 2019. Function and three-dimensional structure of intervessel pit membranes in angiosperms: A review. IAWA J. 40: 673-702.

Kashyap, A., Planas-Marquès, M., Capellades, M., Valls, M., and Coll, N. S. 2020. Blocking intruders: Inducible physico-chemical barriers against plant vascular wilt pathogens. J. Exp. Bot. 72:184-198.

Khokhani, D., Tuan, T., Lowe-Power, T., and Allen, C. 2018. Plant assays for quantifying Ralstonia solanacearum virulence. Bio-protocol 8:e3028.

Kim, T.-H., Bæhmer, M., Hu, H., Nishimura, N., and Schroeder, J. I. 2010. Guard cell signal transduction network: Advances in understanding abscisic acid, $\mathrm{CO}_{2}$, and $\mathrm{Ca}^{2+}$ signaling. Annu. Rev. Plant Biol. 61:561-591.

Liu, H., Zhang, S., Schell, M. A., and Denny, T. P. 2005. Pyramiding unmarked deletions in Ralstonia solanacearum shows that secreted proteins in addition to plant cell-wall-degrading enzymes contribute to virulence. Mol. Plant. Microbe. Interact. 18:1296-1305.

Lorenzini, G., Guidi, L., Nali, C., Ciompi, S., and Soldatini, G. F. 1997. Photosynthetic response of tomato plants to vascular wilt diseases. Plant Sci. 124:143-152.

Lowe-Power, T., Avalos, J., Charco Munoz, M., and Chipman, K. 2020. A meta-analysis of the known global distribution and host range of the Ralstonia species complex. bioRxiv 2020.07.13.189936.

Lowe-Power, T. M., Hendrich, C. G., von Roepenack-Lahaye, E., Li, B., Wu, D., Mitra, R., Dalsing, B. L., Ricca, P., Naidoo, J., Cook, D., Jancewicz, A., Masson, P., Thomma, B., Lahaye, T., Michael, A. J., and Allen, C. 2018. Metabolomics of tomato xylem sap during bacterial wilt reveals Ralstonia solanacearum produces abundant putrescine, a metabolite that accelerates wilt disease. Environ. Microbiol. 20:1330-1349.

Lowe-Power, T. M., Khokhani, D., and Allen, C. 2018. How Ralstonia solanacearum exploits and thrives in the flowing plant xylem environment. Trends Microbiol. 26:929-942.

McElrone, A. J., Choat, B., Parkinson, D. Y., MacDowell, A. A., and Brodersen, C. R. 2013. Using high resolution computed tomography to visualize the three dimensional structure and function of plant vasculature. J. Vis. Exp. 74:50162.

McElrone, A. J., Jackson, S., and Habdas, P. 2008. Hydraulic disruption and passive migration by a bacterial pathogen in oak tree xylem. J. Exp. Bot. 59:2649-2657.

McGarvey, J. A., Denny, T. P., and Schell, M. A. 1999. Spatial-temporal and quantitative analysis of growth and EPS I production by Ralstonia solanacearum in resistant and susceptible tomato cultivars. Phytopathology 89:1233-1239.

Morella, N. M., Yang, S. C., Hernandez, C. A., and Koskella, B. 2018. Rapid quantification of bacteriophages and their bacterial hosts in vitro and in vivo using droplet digital PCR. J. Virol. Methods 259:18-24

Nardini, A., Lo Gullo, M. A., and Salleo, S. 2011. Refilling embolized xylem conduits: Is it a matter of phloem unloading? Plant Sci. 180:604-611.

Opina, N., Tavner, F., Hollway, G., Wang, J. F., Li, T. H., Maghirang, R., Fegan, M., Hayward, A., Krishnapillai, V., Hong, W., Holloway, B. W., and Timmis, J. N. 1997. A novel method for development of species and strain-specific DNA proves and PCR primers for identifying Burkholderia solanacearum (formerly Pseudomonas solanacearum). Asia Pac. J. Mol. Biol. Biotechnol. 5:19-30.

Pérez-Donoso, A. G., Lenhof, J. J., Pinney, K., and Labavitch, J. M. 2016. Vessel embolism and tyloses in early stages of Pierce's disease. Aust. J. Grape Wine Res. 22:81-86.

Pérez-Donoso, A. G., Sun, Q., Roper, M. C., Greve, L. C., Kirkpatrick, B., and Labavitch, J. M. 2010. Cell wall-degrading enzymes enlarge the pore size of intervessel pit membranes in healthy and Xylella fastidiosa-infected grapevines. Plant Physiol. 152:1748-1759.

Planas-Marquès, M., Kressin, J. P., Kashyap, A., Panthee, D. R., Louws, F. J., Coll, N. S., and Valls, M. 2020. Four bottlenecks restrict colonization and invasion by the pathogen Ralstonia solanacearum in resistant tomato. J. Exp. Bot. 71:2157-2171.

Prior, P., Ailloud, F., Dalsing, B. L., Remenant, B., Sanchez, B., and Allen, C. 2016. Genomic and proteomic evidence supporting the division of the plant pathogen Ralstonia solanacearum into three species. BMC Genom. 17:90.

Rahman, M. A., Abdullah, H., and Vanhaecke, M. 1999. Histopathology of susceptible and resistant Capsicum annuum cultivars infected with Ralstonia solanacearum. J. Phytopathol. 147:129-140.

Rajagopal, V., Sumathykuttyamma, B., and Patil, K. D. 1987. Water relations of coconut palms affected with root (wilt) disease. New Phytol. 105: 289-293.

Roper, M. C., Greve, L. C., Warren, J. G., Labavitch, J. M., and Kirkpatrick, B. C. 2007. Xylella fastidiosa requires polygalacturonase for colonization and pathogenicity in Vitis vinifera grapevines. Mol. Plant. Microbe. Interact. 20:411-419.

Schwarze, F. W., and Landmesser, H. 2000. Preferential degradation of pit membranes within tracheids by the basidiomycete Physisporinus vitreus. Holzforschung 54:461-462.

Sperry, J. S., and Hacke, U. G. 2004. Analysis of circular bordered pit function I. Angiosperm vessels with homogenous pit membranes. Am. J. Bot. 91:369-385.

Stevenson, J. F., Matthews, M. A., Carl Greve, L., Labavitch, J. M., and Rost T. L. 2004. Grapevine susceptibility to Pierce's disease II: Progression of anatomical symptoms. Am. J. Enol. Vitic. 55:238-245.

Sun, Q., Greve, L. C., and Labavitch, J. M. 2011. Polysaccharide compositions of intervessel pit membranes contribute to Pierce's disease resistance of grapevines. Plant Physiol. 155:1976-1987.

Sun, Q., Sun, Y., Walker, M. A., and Labavitch, J. M. 2013. Vascular occlusions in grapevines with Pierce's disease make disease symptom development worse. Plant Physiol. 161:1529-1541.

Tyree, M. T., and Sperry, J. S. 1989. Vulnerability of xylem to cavitation and embolism. Annu. Rev. Plant Physiol. Plant Mol. Biol. 40: 19-36.

Tyree, M. T., and Zimmermann, M. H. 2002. Hydraulic architecture of whole plants and plant performance. Pages 175-214 in: Xylem Structure and the Ascent of Sap. M. T. Tyree and M. H. Zimmermann, eds. Springer, Berlin, Germany.

Vasse, J., Frey, P., and Trigalet, A. 1995. Microscopic studies of intercellular infection and protoxylem invasion of tomato roots by Pseudomonas solanacearum. Mol. Plant-Microbe. Interact. 8:241-251.

Weiss, R. F. 1970. The solubility of nitrogen, oxygen and argon in water and seawater. Deep Sea Res. Oceanogr. Abstr. 17:721-735.

Yadeta, K. A., and Thomma, B. P. H. J. 2013. The xylem as battleground for plant hosts and vascular wilt pathogens. Front. Plant Sci. 4:97. 